Review/Meta-analyses

\title{
Longitudinal studies of functional magnetic resonance imaging in first-episode psychosis: A systematic review
}

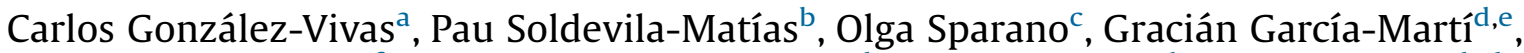 \\ Luís Martí-Bonmatî ${ }^{\text {,f }}$, Benedicto Crespo-Facorro ${ }^{\mathrm{d}, \mathrm{g}}$, André Aleman ${ }^{\mathrm{h}}$, Julio Sanjuan ${ }^{\mathrm{a}, \mathrm{b}, \mathrm{d}, *}$ \\ a Department of Psychiatry, Clinical University Hospital, Valencia, Spain \\ ${ }^{\mathrm{b}}$ INCLIVA Health Research Institute, Clinical University Hospital, Valencia, Spain \\ c Department of Psychiatry, La Ribera University Hospital, Valencia, Spain \\ ' Centro de Investigación Biomédica en Red de Salud Mental (CIBERSAM), Valencia, Spain \\ e Radiology Department, Quirón Hospital, Valencia, Spain \\ ${ }^{\mathrm{f}}$ Radiology Department and GIBI230 Research Group, La Fe University and Polytechnic Hospital, Valencia, Spain \\ ${ }^{g}$ Department of Medicine and Psychiatry, Marqués de Valdecilla University Hospital, Cantabria University, Santander, Spain \\ ${ }^{\mathrm{h}}$ Department of Neuroscience, University of Groningen, University Medical Center Groningen, Groningen, the Netherlands
}

\section{A R T I C L E I N F O}

\section{Article history:}

Received 12 February 2019

Received in revised form 27 April 2019

Accepted 28 April 2019

Available online 7 May 2019

\section{Keywords:}

FEP

Psychosis

Neuroimaging

fMRI

Longitudinal

Review

\begin{abstract}
A B S T R A C T
Background: Little is known about changes in brain functioning after first-episode psychosis (FEP). Such knowledge is important for predicting the course of disease and adapting interventions. Functional magnetic resonance imaging has become a promising tool for exploring brain function at the time of symptom onset and at follow-up.

Method: A systematic review of longitudinal fMRI studies with FEP patients according to PRISMA guidelines. Resting-state and task-activated studies were considered together.

Results: Eleven studies were included. These reported on a total of 236 FEP patients were evaluated by two fMRI scans and clinical assessments. Five studies found hypoactivation at baseline in prefrontal cortex areas, two studies found hypoactivation in the amygdala and hippocampus, and three others found hypoactivation in the basal ganglia. Other hypoactivated areas were the anterior cingulate cortex, thalamus and posterior cingulate cortex. Ten out of eleven studies reported (partial) normalization by increased activation after antipsychotic treatment. A minority of studies observed hyperactivation at baseline.

Conclusions: This review of longitudinal FEP samples studies reveals a pattern of predominantly hypoactivation in several brain areas at baseline that may normalize to a certain extent after treatment. The results should be interpreted with caution given the small number of studies and their methodological and clinical heterogeneity.
\end{abstract}

(C) 2019 Published by Elsevier Masson SAS.

\section{Introduction}

First-episode psychosis (FEP) is characterized by the appearance of psychotic symptoms for the first time in an individual's life. More than $3 \%$ of the general population suffers a psychotic episode at some point in life [1]. The incidence rate is 21.4 per 100,000 person-years, and the average age when the first episode occurs is 30.5 years. However, epidemiologic data must be cautiously interpreted because of the heterogeneity of existing studies [2].

\footnotetext{
* Corresponding author at: Department of Psychiatry, Clinical University Hospital, Valencia, Spain.

E-mail address: julio.sanjuan@uv.es (J. Sanjuan).
}

There is enough evidence to indicate the need to improve and develop tools for early diagnosis and interventions in FEP to improve treatment response, reduce dysfunction and improve the quality of life of patients [3-6].

There is a lack of knowledge regarding why some people fully recover from their symptoms while others tend toward deterioration and chronicity. More longitudinal investigations examining the biological markers of FEP are needed [7].

One of the principal instruments used in biomarker research for FEP is magnetic resonance imaging (MRI) [8]. Many studies have used MRI scans to obtain information about the main volumetric changes in the brain during psychosis over time (the possible secondary effects of medication, the loss of grey matter, etc.) [9]. However, structural changes are not specific and cannot be used as 
predictors in individual cases, so more sensitive instruments are needed [10-13].

Another way to view the brain is with functional MRI (fMRI). Given recent theoretical models of psychosis, fMRI could provide an important means of understanding what happens in the brain during the processing of different stimuli [14-19]. This knowledge could contribute to an understanding of the biological issues underpinning the longitudinal course of psychosis.

To the best of our knowledge, there is only one systematic review focusing on psychotic patients in general [20] and no systematic reviews of longitudinal fMRI studies in FEP patients. Hence, the purpose of this review is to systematically gather, analyse and review longitudinal fMRI studies in FEP patients with a specific focus on the relevance of methodology, the different paradigms used during scans and the mode of presentation. We think this review could show different methodological biases and activation results to explore their relationships and contribute to the methodological optimization of fMRI studies. In addition, we expect to elucidate the longitudinal changes in the brain and to shed some light on treatment effects in FEP.

\section{Materials and methods}

This review was methodologically outlined as a protocol prepared according to the PRISMA guidelines [21,22].

\subsection{Inclusion criteria}

- A longitudinal design involving at least two fMRI scans performed at different times with any interval between them.

- Functional data, including activation or functional connectivity (FC) results.

- Task-activated or resting-state fMRI paradigms.

- Clinical studies with control groups.

- Psychotic spectrum diagnoses (schizophrenia, schizophreniform disorder, bipolar disorder, schizoaffective disorder, brief psychotic episode and psychosis not otherwise specified) verified by structured clinical interviews.

- First-episode samples, defined as individuals who had been diagnosed with a psychotic disorder for the first time in their

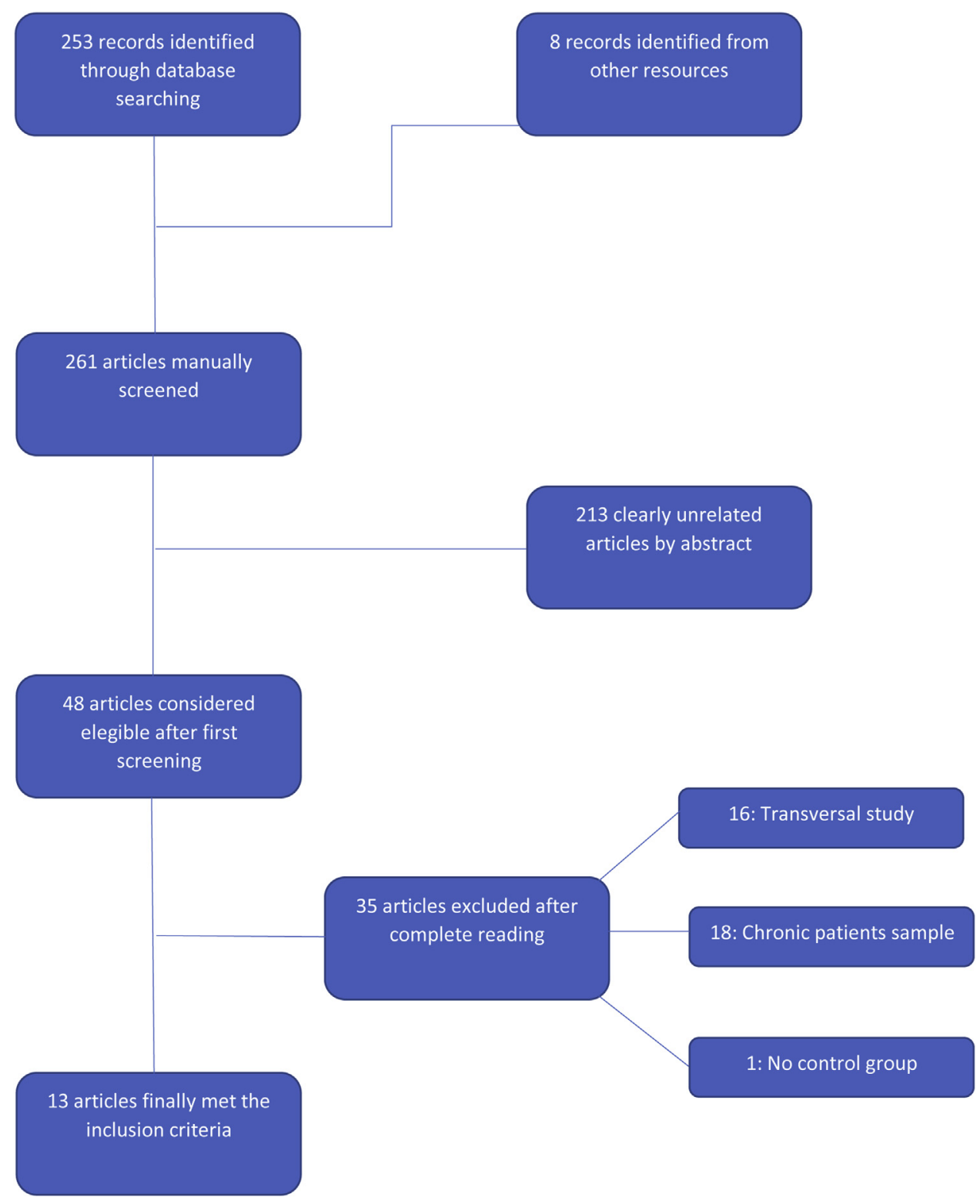

Fig. 1. The results, of every step, in the inclusion process of fMRI longitudinal studies of FEP. 
Longitudinal studies of fMRI in First Episode Psychosis.

\begin{tabular}{|c|c|c|c|c|c|c|c|c|c|c|}
\hline \multirow{2}{*}{$\begin{array}{l}\text { First autor and } \\
\text { year }\end{array}$} & \multirow[t]{2}{*}{ FEP Sample } & \multirow[t]{2}{*}{ Scales } & \multirow[t]{2}{*}{ Medication } & \multirow[t]{2}{*}{ DUI } & \multirow{2}{*}{$\begin{array}{l}\text { Number of } \\
\text { scans and } \\
\text { time } \\
\text { between } \\
\text { scans }\end{array}$} & \multirow[t]{2}{*}{ ROI } & \multirow[t]{2}{*}{ Paradigm and task } & \multicolumn{2}{|l|}{ Results } & \multirow[t]{2}{*}{ Comments } \\
\hline & & & & & & & & Pre & Post & \\
\hline Snitz, 2005 & $\begin{array}{l}\mathrm{N}=11 \\
\text { Age: } 23 \\
\text { Male: } 70 \% \\
\text { Diagnoses: FES }\end{array}$ & $\begin{array}{l}\text { SCID-I } \\
\text { BPRS }\end{array}$ & $\begin{array}{l}\text { Naïve at baseline. } \\
\text { At follow-up: risperidone } \\
(\mathrm{n}=7) 1-4 \mathrm{mg} / \text { day; olanzapine } \\
(\mathrm{n}=3) 5-10 \mathrm{mg} / \text { day; quetiapine } \\
(\mathrm{n}=1) 300 \mathrm{mg} / \text { day. }\end{array}$ & $\begin{array}{l}\text { Not } \\
\text { specified }\end{array}$ & $\begin{array}{l}2 \text { scans } \\
1 \text { month }\end{array}$ & $\begin{array}{l}\text { DLPFC and } \\
\text { ACC }\end{array}$ & $\begin{array}{l}\text { Visual stimuli in } \\
\text { cognitive control } \\
\text { task }\end{array}$ & $\begin{array}{l}\text { Hypoactivation in } \\
\text { DLPFC and ACC. }\end{array}$ & $\begin{array}{l}\text { Increased activation in } \\
\text { ACC but not in DLPFC. }\end{array}$ & $\begin{array}{l}\text { DLPFC dysfunction } \\
\text { associated with } \\
\text { negative symptoms } \\
\text { before treatment. }\end{array}$ \\
\hline Reske, 2007 & $\begin{array}{l}\mathrm{N}=10 . \\
\text { Age: } 37.4 \\
\text { Male: } 60 \% \\
\text { Diagnoses: FES }\end{array}$ & $\begin{array}{l}\text { SCID-I } \\
\text { PANSS }\end{array}$ & $\begin{array}{l}\text { Under treatment at baseline } \\
\text { and at follow-up: double blind } \\
\text { with haloperidol }(n=5) 2,6 \mathrm{mg} / \\
\text { day or risperidone }(n=5) \\
2,6 \mathrm{mg} / \text { day. }\end{array}$ & $\begin{array}{l}\text { Not } \\
\text { specified }\end{array}$ & $\begin{array}{l}2 \text { scans } \\
6 \text { months }\end{array}$ & $\begin{array}{l}\text { Emotional } \\
\text { processing } \\
\text { regions }\end{array}$ & $\begin{array}{l}\text { Mood induction } \\
\text { (happiness and } \\
\text { sadness) using } \\
\text { visual stimuli }\end{array}$ & $\begin{array}{l}\text { Hypoactivations in } \\
\text { regions of emotional } \\
\text { processing like right } \\
\text { ACC, OFC and ATP and } \\
\text { subcortical regions like } \\
\text { the caudate, thalamus } \\
\text { and hippocampus. } \\
\text { Hyperactivation in } \\
\text { cerebellum. }\end{array}$ & $\begin{array}{l}\text { Increased activation in } \\
\text { the pre and post central } \\
\text { gyri and in the inferior } \\
\text { frontal cortex and } \\
\text { temporal areas. } \\
\text { Stability of other } \\
\text { hypoactivations. }\end{array}$ & $\begin{array}{l}\text { Stability of } \\
\text { emotional } \\
\text { dysfunctions is } \\
\text { associated with } \\
\text { negative symptoms }\end{array}$ \\
\hline $\begin{array}{l}\text { Van Veelen, } \\
2011\end{array}$ & $\begin{array}{l}\mathrm{N}=23 \\
\text { Age: } 25.3 \\
\text { Male: } 100 \% \\
\text { Diagnoses: FES (12 } \\
\text { schizophrenia and } 11 \\
\text { schizophreniform } \\
\text { disorder) }\end{array}$ & $\begin{array}{l}\text { SCID-I } \\
\text { MINI } \\
\text { PANSS }\end{array}$ & $\begin{array}{l}\text { Naïve at baseline. } \\
\text { At follow-up: olanzapine } \\
(\mathrm{n}=13) 15 \mathrm{mg} / \text { day; risperidone } \\
(\mathrm{n}=4) 4 \mathrm{mg} / \mathrm{day} \text {; quetiapine } \\
(\mathrm{n}=3) 733 \mathrm{mg} / \text { day; ziprasidone } \\
(\mathrm{n}=3) 65 \mathrm{mg} / \text { day. }\end{array}$ & 4,9 months & $\begin{array}{l}2 \text { scans } \\
10 \text { weeks }\end{array}$ & $\begin{array}{l}\text { Left } \\
\text { fusiform } \\
\text { gyrus, left } \\
\text { and right } \\
\text { superior } \\
\text { parietal } \\
\text { cortex, ACC } \\
\text { and DLPFC }\end{array}$ & $\begin{array}{l}\text { Visual stimuli in a } \\
\text { working memory } \\
\text { task }\end{array}$ & $\begin{array}{l}\text { Hypoactivation in } \\
\text { DLPFC. }\end{array}$ & $\begin{array}{l}\text { Normalization in good } \\
\text { responders to } \\
\text { treatment. Persistent } \\
\text { hypoactivation in } \\
\text { nonresponders. }\end{array}$ & $\begin{array}{l}\text { Prefrontal lobe } \\
\text { dysfunction } \\
\text { predicts treatment } \\
\text { response. }\end{array}$ \\
\hline Nielsen, 2012 & $\begin{array}{l}\mathrm{N}=23 \\
\text { Age: } 26 \\
\text { Male: } 70 \% \\
\text { Diagnoses: FES (13 } \\
\text { paranoid, } 8 \\
\text { undifferentiated, } 1 \\
\text { simplex) and } 1 \\
\text { schizoaffective } \\
\text { disorder }\end{array}$ & $\begin{array}{l}\text { ICD-10 } \\
\text { criteria } \\
\text { GAF } \\
\text { PANSS }\end{array}$ & $\begin{array}{l}\text { Naïve at baseline. } \\
\text { At follow-up amisulpride } \\
300 \mathrm{mg} \text {. }\end{array}$ & $\begin{array}{l}\text { Not } \\
\text { specified }\end{array}$ & $\begin{array}{l}2 \text { scans } \\
6 \text { weeks }\end{array}$ & Striatum & $\begin{array}{l}\text { Visual detection of } \\
\text { targets and reward } \\
\text { anticipation }\end{array}$ & $\begin{array}{l}\text { Hypoactivation in } \\
\text { bilateral ventral } \\
\text { striatum. }\end{array}$ & $\begin{array}{l}\text { Increased activation in } \\
\text { right ventral striatum. }\end{array}$ & $\begin{array}{l}\text { Reward-related } \\
\text { system activation } \\
\text { correlates with } \\
\text { clinical } \\
\text { improvement }\end{array}$ \\
\hline Bergé, 2014 & $\begin{array}{l}\mathrm{N}=18 \\
\text { Age: } 24.83 \\
\text { Male: } 55 \% \\
\text { Diagnoses: FES (13 } \\
\text { schizophreniform } \\
\text { disorder, } 2 \\
\text { schizophrenia, } 1 \text { brief } \\
\text { psychotic disorder, } 1 \\
\text { schizoaffective } \\
\text { disorder and } 1 \\
\text { psychosis NOS) }\end{array}$ & $\begin{array}{l}\text { SCID-I } \\
\text { PANSS } \\
\text { SUMD } \\
\text { (Insight) }\end{array}$ & $\begin{array}{l}\text { Naïve at baseline. } \\
\text { At follow up: risperidone } \\
\text { (389\%) } 7,3 \mathrm{mg} / \text { day; olanzapine } \\
(556 \%) 17 \mathrm{mg} / \text { day; aripiprazole } \\
(5,6 \%) 30 \mathrm{mg} / \text { day. }\end{array}$ & $\begin{array}{l}\text { Not } \\
\text { specified }\end{array}$ & $\begin{array}{l}2 \text { scans } \\
3-6 \text { weeks }\end{array}$ & $\begin{array}{l}\text { Limbic } \\
\text { system }\end{array}$ & $\begin{array}{l}\text { Visual } \\
\text { discrimination of } \\
\text { emotional or } \\
\text { neutral faces, } \\
\text { representing fear, } \\
\text { anger, disgust or } \\
\text { happiness } \\
\text { expressions. }\end{array}$ & $\begin{array}{l}\text { Hypoactivation in } \\
\text { ventro-limbic regions } \\
\text { (amygdala and right } \\
\text { hippocampus), ventral- } \\
\text { posterior regions } \\
\text { (bilateral lingual gyrus, } \\
\text { calcarine fissure and } \\
\text { occipital superior } \\
\text { gyrus) and fronto- } \\
\text { temporal regions. }\end{array}$ & $\begin{array}{l}\text { Increased activation in } \\
\text { amygdala, lingual gyrus } \\
\text { and calcarine fissure. }\end{array}$ & $\begin{array}{l}\text { Selective } \\
\text { hypoactivations of } \\
\text { ventral limbic } \\
\text { system, improved } \\
\text { with antipsychotics }\end{array}$ \\
\hline Ikuta, 2014 & $\begin{array}{l}\text { N=14 } \\
\text { Age: } 22 \\
\text { Male: } 100 \% \\
\text { Diagnoses: FES ( } 11 \\
\text { schizophrenia, } 2 \\
\text { psychosis NOS and } 1 \\
\text { schizophreniform } \\
\text { disorder) }\end{array}$ & $\begin{array}{l}\text { SCID-I } \\
\text { BPRS }\end{array}$ & $\begin{array}{l}\text { At baseline: } 5 \text { days exposure to } \\
\text { antipsychotic medication ( } 5 \mathrm{mg} \\
\text { aripiprazole or } 1 \mathrm{mg} \\
\text { risperidone). } \\
\text { At follow-up: doses reached } \\
\text { maximums of } 30 \mathrm{mg} \\
\text { aripiprazole and } 6 \mathrm{mg} \text { of } \\
\text { risperidone + lorazepam when } \\
\text { anxiety or agitation. }\end{array}$ & $\begin{array}{l}\text { Not } \\
\text { specified }\end{array}$ & $\begin{array}{l}2 \text { scans } \\
3 \text { months }\end{array}$ & $\begin{array}{l}\text { Basal } \\
\text { ganglia and } \\
\text { thalamus }\end{array}$ & $\begin{array}{l}\text { Visual stimuli in } \\
\text { cognitive control } \\
\text { task }\end{array}$ & $\begin{array}{l}\text { Hyperactivation in } \\
\text { basal ganglia, specially } \\
\text { globus pallidus. }\end{array}$ & $\begin{array}{l}\text { Decreased activation } \\
\text { after treatment, } \\
\text { correlated with } \\
\text { symptoms } \\
\text { improvement. }\end{array}$ & $\begin{array}{l}\text { Basal ganglia play a } \\
\text { role in thought } \\
\text { disturbance. }\end{array}$ \\
\hline
\end{tabular}


Hypoactivation in the and motor learning neocortical network

shizoaffective

schizophreniform

disorder)

Sarpal, 2015

At baseline: mean of 4.5 days of antipsychotic exposure. 


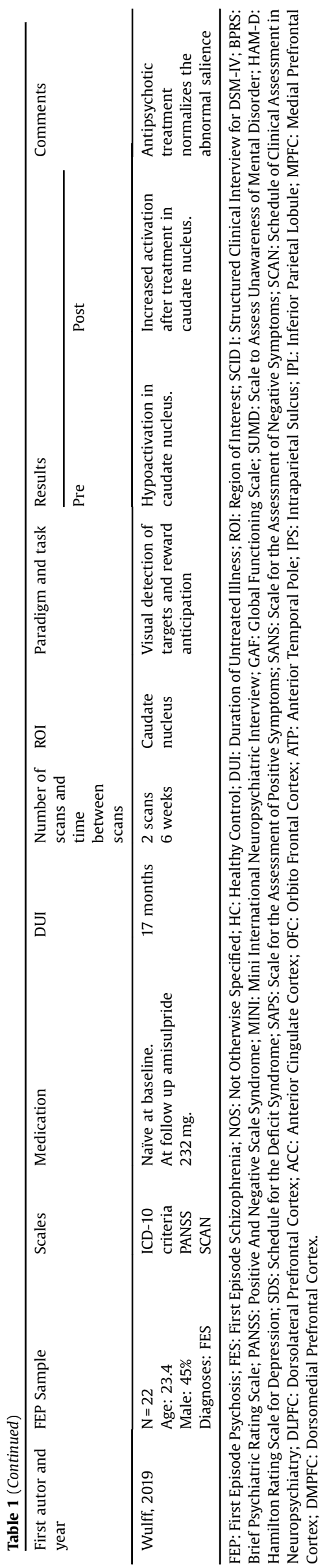

lives and were assessed and scanned for the first time within the first 18 months after symptom onset.

\subsection{Exclusion criteria}

- Morphometric (MRI, DTI ... ) results.

- Epidemiological studies, reviews and meta-analyses.

- No psychosis spectrum diagnoses.

- Inclusion of chronic patients, defined as those who have had one or more previous psychotic disorder diagnosed in their lifetime, or those who were scanned more than 18 months after the onset of symptoms.

\subsection{Study search, selection and data extraction}

A systematic search was conducted by two independent researchers (CG-V and PS-M) using the query ("longitudinal" and "fMRI" and "schizophrenia") combined with ("longitudinal" and "fMRI" and "psychosis") in the PubMed, MEDLINE and Web of Science (WOS) databases on April 2019. There was potential for an overlap in the final number of studies found due to the multiple databases employed.

These automatic searches were complemented by manual reviews of the references of the eligible articles after the final screening.

The selection of these datasets was performed hierarchically. An initial screening was performed based on the title and abstract, and a second screening was performed based on the full article reading.

Data were extracted using a table that addressed the following points: 1) author and year of publication, 2) sample data, including number of cases, mean age, percentage of males and diagnoses, 3 ) clinical assessment scales, 4) medication, 5) duration of illness and untreated period, 6) number of scans and intervals between them, 7) approach used (region of interest (ROI) or global), 8) paradigm and task applied, 9) results, according to hypo/hyper activation at baseline or follow-up and 10) comments regarding the discussion.

Given the very few articles that were finally included and the small resulting sample size, we decided to include both task and resting-state paradigms in the same table. The table summarizes the methodology of the studies, and their possible relationship with results will be examined in the discussion.

\subsection{Neuroimaging acquisition and data processing}

The MR field strength reported in the selected articles was either 1.5 or $3 \mathrm{~T}$. Scans were performed by neuroimaging experts. There was high heterogeneity in the software tools used for data processing and brain mapping. Activation and connectivity studies were both considered.

\section{Results}

\subsection{Included studies and sample description}

The results of every step in the inclusion process are summarized in Fig. 1. A total of 13 clinical studies were included [23-35]. By aggregating the included samples, a total of 290 FEP patients and 401 healthy volunteers were assessed. The mean age of the patients was 24.55 years old, and the mean age of the controls was 29.9 years. Males comprised more than half of the study population (62\% in both experimental and control groups). Every participant was scanned twice, with an average interval of 4.76 months between scans. 
Diagnoses were made according to the DSM-IV-TR or ICD-10 criteria in every included article. Nine out of 13 studies used the Positive and Negative Symptom Scale (PANSS) for psychotic symptom measurement. The Brief Psychotic Rating Scale (BPRS) was used instead of the PANSS in 4 studies. The Global Assessment of Functioning (GAF) was used in 4 studies for global function measurement. Other clinical scales were used in only one study each and included the following: the Hamilton Depression Scale (HAM-D), the Mini International Neuropsychiatric Interview (MINI), the Scale to Assess Unawareness of Mental Disorder (SUMD) to evaluate insight, the Scale for the Assessment of Positive Symptoms (SAPS), the Scale for the Assessment of Negative Symptoms (SANS) and the Schedule of Clinical Assessment in Neuropsychiatry (SCAN).

\subsection{Methodological issues}

The articles included in this review showed important methodological heterogeneity.

Regarding article design, only 3 out of the 13 included articles used a double-blinded medication approach; these studies were interested in investigating the differences in different antipsychotic effects $[24,25,35]$. The remaining 10 studies implemented naturalistic designs with longitudinal follow-up of clinically selected samples treated according to a psychiatrist's criteria.

In all studies, the main diagnosis was first-episode schizophrenia (FES), although 4 studies [27,31,32,34] included also patients with schizoaffective disorder. Nine out of 13 studies reported medication naïve patients at baseline, but all of the patients were receiving psychopharmacological treatment at follow-up assessment. Different antipsychotics were managed in the pharmacological treatments. Most of studies applied atypical antipsychotic medications, but 1 study implemented typical antipsychotic treatment (haloperidol) in a half of its patients [24]. Antipsychotic doses are fully described in Table 1.

Second, the ROI approach was implemented in 12 of the 13 included studies. Specifically, the striatum, but also the prefrontal cortex, basal ganglia, hippocampus and limbic system, were the most investigated brain areas. The global approach was used in 1 study [29], and there were 2 articles investigating specific functional networks involving emotional processing (the anterior cingulate cortex, pre-post central gyri and inferior frontal and temporal areas) [24] and motor learning areas (the dorsal prefrontal cortex and striatum) [34].

Third, a resting-state paradigm was used in 4 of 13 studies. In these studies, images are obtained using no task in particular, and the results reflect the spontaneous fluctuation of the blood oxygen level-dependent (BOLD) signal. In contrast, 9 studies presented some kind of visual stimuli during fMRI scans to develop task paradigms. Two of them presented pictures of human facial emotional expressions to induce a mood or discriminate emotions [24,32]. Four other articles used a cognitive control paradigm $[23,25,27,34]$. For this purpose, Snitz et al. [23] developed an overcome prepotency task in which the subject received visual targets (arrows pointing to left or right) and had to respond with ipsilateral or contralateral button that would be pressed depending on the target's colour. In the Ikuta et al. study [25], subjects completed the Multi-Source Interference Task (MSIT) to assess attentional control by the identifying targets with interference between the target number and the key. In the Keedy et al. study [34], subjects tracked a white dot along its relocations over the horizontal meridian. Two other studies implemented a reward paradigm to explore the benefits of medication for the brain's reward system by changing the certainty of monetary gains according to the participants' correct responses to target detection tasks [26,31]. Finally, one study developed a visual working memory task by presenting a memory set of 5 digits for $5 \mathrm{~s}$, followed by series of target discrimination tasks [30].

Fourth, in terms of the presentation of the results, 3 of the 13 studies reported FC results [29,33,35], presenting BOLD signal changes in networks that involve different brain structures. The other 10 studies presented the results according to the BOLD activation level differences in seed regions.

\subsection{Longitudinal changes}

Taken together, most of the included studies reported findings of hypoactivation in several brain areas during the basal assessment. Different studies found hypoactivation in the prefrontal cortex (PFC) areas [23,24,27,29,30,33,34] and limbic regions, specifically the amygdala and hippocampus [24,29,32,34]. Hypoactivation was also found in regions such as the basal ganglia, particularly the striatum [24,26,31], anterior cingulate cortex (ACC) [23,24], thalamus [24,29], bilateral precuneus [29] and posterior cingulate cortex (PCC) [34] (Fig. 2).

On the other hand, 5 studies reported some kind of hyperactivation at baseline. One study reported hyperconnectivity around medial prefrontal cortex (MPFC) regions [33]. Two studies reported hyperactivation of the basal ganglia $[25,28]$. One article reported hyperactivation of the cerebellum in a patient group [24], but only during sadness processing. Finally, one study found hyperconnectivity between the right orbitofrontal cortex (ROFC)

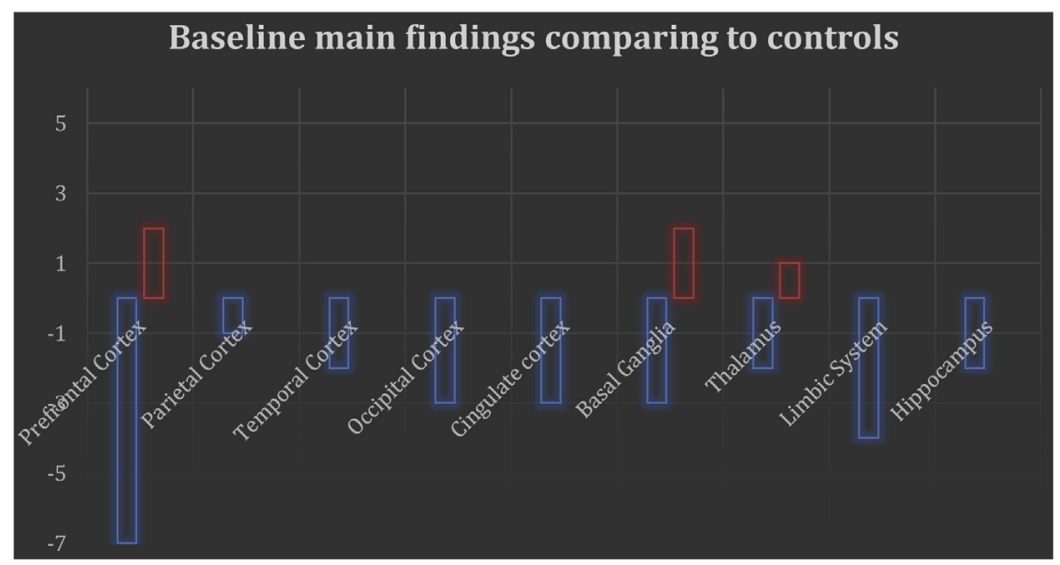

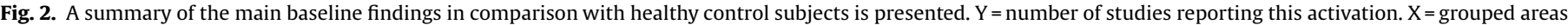

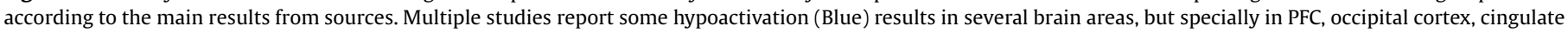
cortex, basal ganglia and limbic system (For interpretation of the references to colour in this figure legend, the reader is referred to the web version of this article). 


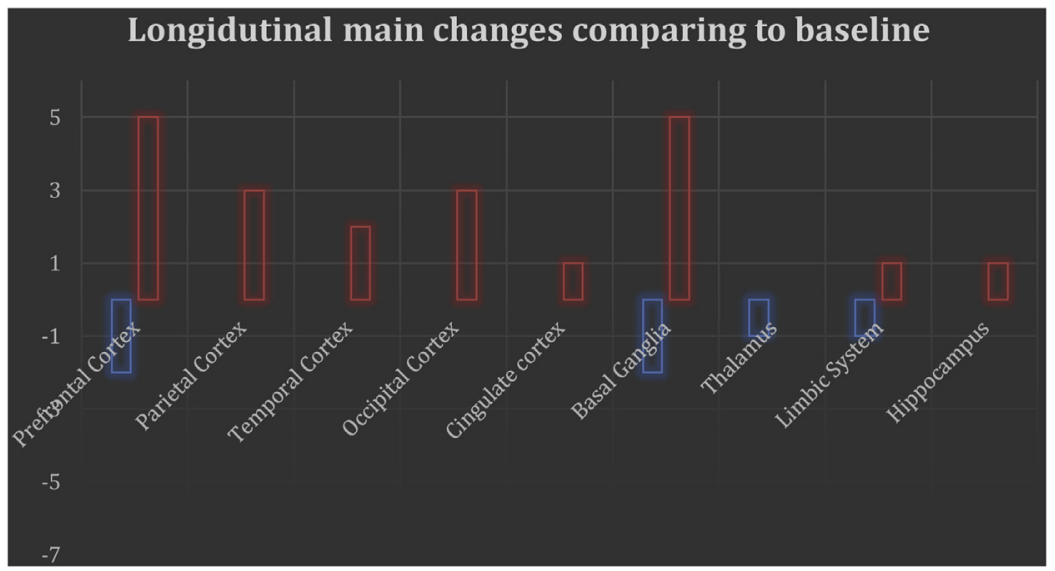

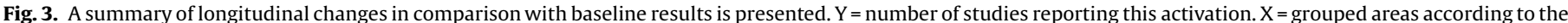

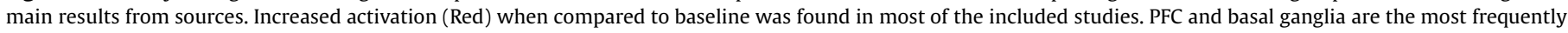
activated areas after treatment. (For interpretation of the references to colour in this figure legend, the reader is referred to the web version of this article).

and the dorsolateral prefrontal cortex (DLPFC) [29]. Just one included article reported no differences between patients and healthy control groups [35].

At follow-up, the main result was increased activation in those hypoactivated regions [23,26,29-35], which could be interpreted as normalization. Most of studies reported increased activation in PFC (OFC, DLPFC and MPFC) and basal ganglia but also in cingulate cortex, limbic system, parietal cortex, temporal cortex and thalamus. Some studies reported marginally decreased activations respect to pretreatment scans in the DLPFC [34], right accumbens [35], MPFC [33] and parietal cortex areas [29,35]. Only one study reported as a main result a decrease in activation in the basal ganglia and thalamus [36]. A summary of the main longitudinal changes can be found in Fig. 3.

Based on the differences in results, different explanatory hypotheses were proposed by the original authors. The dopamine hypothesis of schizophrenia was used in one study [28]. Two studies linked the imaging results with the aberrant salience hypothesis [26,35], which could be considered a version of the dopamine hypothesis. Meanwhile, one study considered the expanded dopamine hypothesis [34], and another proposed the dopamine and serotonin hypothesis [29]. One study was interpreted to support the disconnection syndrome [33]. One study was interpreted to support the neurodevelopmental hypothesis for schizophrenia [27]. The other 6 studies proposed design-specific interpretations related to treatment response.

\section{Discussion}

In the present review, we examined longitudinal fMRI studies in FEP samples and found general hypoactivation in pretreatment scans that was reduced ("normalized") in the follow-up and after the administration of antipsychotic treatment. Regarding the implicated areas, there is a dependent relationship between results, seed regions and tasks. The main hypoactivated areas were the PFC (OFC, DLPFC and MPFC), the basal ganglia (caudate nucleus and striatum), the limbic system (the amygdala and insula), the hippocampus and the ACC. We also found hypoconnectivity in the included FC studies, which also tended to normalize at follow-up scans.

Notably, there are few papers reporting longitudinal follow-ups of FEP patients, so we considered all those that were available, including resting-state and task-activation designs. Of the 13 included studies, 4 used resting-state scans, and the other 9 studies presented different paradigms (mood induction, emotion discrimination, reward anticipation, working memory and cognitive control) in visual modalities.

Despite the commonalities, there are some different contributions that deserve to be discussed. Two of the three longest (more than 12 months between scans) articles [33,37] were based on resting-state scans, but they reported different results, which may in part be due to their different ROI. Anticevic et al. [33] studied the PFC as an ROI, and reported hypo- and hyperconnectivity at baseline in the MPFC and DLPFC regions, respectively. Li et al. [29] reported several hypoconnected areas across the brain in their global approach to image processing. Niendam et al. [27] studied the DLPFC using a task, with a long interval between scans (15 months) and they reported the absence of deterioration during the first 2 years of the illness in a very young patients sample.In contrast, Anticevic et al. reported stability of the DLPFC disfunctions starting with the youngest sample that we included in this review. The interpretation of these results is based on the neurodevelopmental hypothesis of schizophrenia, in which deficits emerge before illness onset.

According to the employed task, Snitz et al. [23], Ikuta et al. [25], and Niendam et al. [27] implemented cognitive control paradigms and reported different findings (hypoactivation in the DLPFC and ACC versus hyperactivation in the basal ganglia and thalamus). Consequently, differences in the ROI approach (DLPFC and ACC versus the basal ganglia and thalamus), longer intervals between scans and different medication states at baseline (naïve versus prior antipsychotic exposure) must be considered for interpretation. The two studies that implemented emotional paradigms [24,32] found hypoactivation of its ROIs. They used different task and time intervals, but both reported some selective treatment effects resulting in the normalization of aberrant activation in some emotional processing areas, and both link their results with positive improvement in symptoms; and the stability of dysfunctions is more associated with negative symptoms. An important contribution comes from the Danish group, which has published two articles [26,31] using the same task paradigm and the same antipsychotic medication (amisulpride). The results vary according to the ROI, but they are consistent with the basal ganglia hypoactivation at baseline and the normalization after treatment.

We also found that the time between symptom onset and the first scan was not normally specified in our selected studies. Only the most recent articles included this important information for FEP samples categorization. According to the sample size, the largest study [39] $(n=42)$ only reported hyperactivation of its ROI (striatum) at baseline that increased after treatment. This is one of 
the two articles [28,37] that used amplitudes of low frequency fluctuations (ALFF), fractional ALFF (fALFF) and regional homogeneity (ReHo) indices to show spontaneous brain activity during resting-state fMRI scans. They linked these results to the compensatory effects of treatment.

Regarding the use of medication at baseline, Sarpal et al. [35] scanned subjects with prior exposure to antipsychotics; their study is the only one in our review to report no significant differences at baseline between patients and control subjects. It also linked symptom improvement to increased connectivity in cortical areas and decreased connectivity in subcortical areas, normalizing the salience system.

Most of the studies linked their results with clinical variables. Nielsen et al. [31] reported clinical improvement as patients obtained normalization as a brain reward system. Van Veelen et al. [30] reported normalization at the DLPFC after treatment in only a subgroup of patients (responders) versus persistent hypoactivation at the DLPFC in non-responders. Finally, only Keedy et al. [34] reported some adverse effects of medication resulting from hypoactivation at the DLPFC after treatment administration.

Other reviews have studied the longitudinal results of fMRI in chronic schizophrenia samples [20]. In these reviews the most consistently reported finding is "normalization" or increased activation in frontal cortical regions, a finding that was consistent with our results. Decreased prefrontal activation (hypofrontality) has been reported in other neuroimaging reviews of chronic patients and is linked with negative symptoms and antipsychotic response [40]. In a recent study [41] of the relationship between BOLD signals and glutamate levels in the salience network (SN) and the default mode network (DMN) during resting-state scans in a sample of schizophrenia patients, the authors found a positive correlation between glutamate levels and activation in the HC group and in the SZ medicated group (positive but decreased at baseline), but a negative relationship in the SZ non-medicated groups. After 6 weeks, all the SZ patients were receiving antipsychotic treatment, and they all showed a positive correlation between glutamate levels and BOLD signals, but with significantly lower activation compared to the HC group in the SN (ACC and bilateral insula) and DMN (precuneus). Regarding other key brain areas, Blasi et al. [42] studied longitudinal changes in a schizophrenia sample and found hyperactivation in the left amygdala and hypoactivation in the right ventrolateral prefrontal cortex (VLPFC) during emotional processing in the SZ group at baseline compared to healthy controls. Both activation alterations were normalized after 8 weeks of treatment with olanzapine. Attending to the hippocampal network, Duan et al. [43], studied FC in a sample with schizophrenia over the course of 24 months. They found hypoconnectivity between the left hippocampal network and the bilateral cerebellum at baseline. After 2 years, decreased FC in the left hippocampal network and increased FC in the right hippocampal network was observed. The authors proposed the disconnection syndrome as an explanatory hypothesis.

As opposed to the very few longitudinal fMRI studies in FEP samples, there are many longitudinal studies that analyse structural neuroimaging results. In a recent review [44], some studies reported significant grey matter loss in the frontal regions, thalamus and total brain volume. They also reported progressive cortical thinning in the superior and inferior frontal cortex and superior temporal cortex. White matter (WM) remained unclear due to contradictory results of recent studies reporting higher WM with longer periods of antipsychotic exposure. In spite of everything, linking structural and functional neuroimaging findings remains a challenge for researching.

In terms of limitations, it should be noted that the included studies present some important biases in sample selection. First, the sample size of most of the fMRI studies in general, but the longitudinal studies in particular, was small, typically approximately 20 subjects per group. Second, longitudinal course information such as symptom onset or its duration is frequently poorly described, which posed problems when categorizing articles as studies of FEP, high-risk individuals or chronic psychotic patients. Third, the included articles selected groups of patients with different ages, but they are balanced with healthy control groups by age and gender. Fourth, there were different medication and dose selections. Typical and atypical antipsychotics were used for treatment, and we consider that a potential area of confusion when interpreting the results. In general, antipsychotic treatment helps to normalize the BOLD signal in most cerebral regions, even in the first weeks of treatment [45]. Fifth, although all the included patients were on non-affective psychosis spectrum, there could be an important heterogeneity in the phenotypes of the included studies. This bias could be fixed by selecting more homogeneous samples with a specific phenotype.

Another very relevant methodological issue is paradigm selection. The type of paradigm selected is a key to understanding fMRI results [46]. Different tasks have been reported to activate different regions [47]. In general, task-activated studies reported hypoactivations at baseline, while resting-state studies found both hypo and hyperactivations in basal assessments.

Our reviewed task studies mainly reported hypoactivations in the involved areas by their specific task and modality. When the task involves emotional processing, hypoactivations in the PFC, OPFC, ACC, amygdala and ventro-limbic region are reported. In the reward learning task, decreased activation of the striatum was found. In the visual cognitive control task, the involved areas were the DLPFC, ACC, left intraparietal sulcus (IPS), left lentiform nucleus, PCC, bilateral insula and visual cortex. A general decrease in activation was found in these areas.

Our group found important differences in activation (hyperactivation at baseline) and involved brain areas (notably the amygdala) in hallucinatory patients with an emotional auditory paradigm [48], again suggesting a decisive influence of the selected paradigm.

On the other hand, resting-state studies reported both hypoactivations and hyperactivations at baseline. The differences in the areas' activation could be explained by the methodological approach used. Hypoconnectivity between the left hippocampal network and the bilateral posterior lobe of the cerebellum was reported when the ROI was the hippocampal network. MPFC and lateral prefrontal cortex (LPFC) hypoconnectivity was found when the ROI was the prefrontal cortex, and increased activation of the left caudate nucleus and putamen was found in a striatum ROI approach.

Despite these important differences, we decided to combine task-activation and resting-state paradigms because of the lack of longitudinal studies found for each one. Recent studies have reported a convergent hypoactivation effect for the task-activation and resting-state studies in the fronto-temporal pathway that involves regions such as the DLPFC, OFC and superior temporal gyrus (STG) [49].

Regarding the resting-state paradigm, an important issue must be considered. In this paradigm, the investigation subject has to "not to think in something in particular" and wait until the end of the scan. Thus, there is no way to control the internal mental processes that could be modulating brain activation images during the scan [50].

Another important factor to consider is the difficulty of precisely determining the time interval between symptom onset and the first clinical assessment and treatment. Psychotic episodes sometimes start with negative symptoms, which are often hard to place along a timeline. We must also consider the different intervals between scans. In general, when the aim of the study is to 
follow the course of the illness, there is a longer period between scans (12 months or longer); in contrast, when the aim of the study is to demonstrate a specific treatment effect, we found shorter intervals (from 1 to 3 months).

In line with the observed heterogeneity in methodology, different interpretations have been proposed for the frequently reported result of normalization after treatment. Methodological homogeneity could help to establish a common theoretical framework. At the moment, the salience model offers an interesting framework for linking biological, clinical and neuroimaging findings. It has to be considered that longitudinal brain studies involving presentation modes other than visual or cognitive paradigms could show interesting results. We think that the development of simpler and more homogeneous paradigms, perhaps involving other modes of presentation, could help us to link this biological and clinical knowledge.

Our review has some limitations. First, there was a small number of longitudinal fMRI studies with FEP samples, so considered all that were available, including task-activation and resting-state paradigms. Second, small sample sizes are very common in functional neuroimaging studies due to the difficulty of recruiting and following an FEP sample over time and the high cost of assessment with fMRI scans. Third, there was no standardization of medications or doses, which could clearly affect the results. Fourth, there was considerable methodological heterogeneity in the included studies. Greater homogeneity of methods is needed to integrate different studies. Fifth, greater clinical heterogeneity in FEP patients than chronic psychosis patients has been reported [51]. This finding is important because some clinical symptoms (negative symptoms) early in the course of the illness may predict more severe mid-term outcomes [52]. Sixth, regarding the followup, longer periods are needed to allow a naturalistic observation, which could help provided a prognosis beyond the treatment response.

\section{Conclusions}

To the best of our knowledge, this is the first review of longitudinal fMRI studies of FEP patients. We summarized the problems of longitudinal neuroimaging follow-ups and their methodological heterogeneity. The main finding was the normalization of brain activity after treatment. Although fMRI seems a promising tool for finding a biological marker of the illness, the mechanisms that distinguish which FEP patients will convert to chronic disease from those who will obtain a full recovery from symptoms have not been clarified. More longitudinal studies with larger samples and simpler and more replicable paradigms could help us to improve our knowledge of this illness and fill the gap between research and clinical practice.

\section{Funding}

This study was supported by grants from the Consellería de Educación (PROMETEO/2016/082) and Carlos III Health Institute (ISCiii PI17/00402) cofunded by The European Union through FEDER funds.

\section{References}

[1] Perälä J, Suvisaari J, Saarni SI, Kuoppasalmi K, Isometsä E, Pirkola S, et al. Lifetime prevalence of psychotic and bipolar I disorders in a general population. Arch Gen Psychiatry 2007;64:19, doi:http://dx.doi.org/10.1001/ archpsyc.64.1.19.

[2] Jongsma HE, Gayer-Anderson C, Lasalvia A, Quattrone D, Mulè A, Szöke A, et al. Treated incidence of psychotic disorders in the multinational EU-GEI study. JAMA Psychiatry 2018;75:36-46, doi:http://dx.doi.org/10.1001/ jamapsychiatry.2017.3554.
[3] Linszen D, Dingemans P, Lenior M. Early intervention and a five year follow up in young adults with a short duration of untreated psychosis: ethical implications. Schizophr Res 2001;51:55-61.

[4] Arango C. First-episode psychosis research: time to move forward (by looking backwards). Schizophr Bull 2015;41:1205-6, doi:http://dx.doi.org/10.1093/ schbul/sbv126.

[5] Berk M, Hallam K, Malhi GS, Henry L, Hasty M, Macneil C, et al. Evidence and implications for early intervention in bipolar disorder. J Ment Health 2010;19:113-26, doi:http://dx.doi.org/10.3109/09638230903469111.

[6] Rosa AR, González-Ortega I, González-Pinto A, Echeburúa E, Comes M Martínez-Àran A, et al. One-year psychosocial functioning in patients in the early vs. late stage of bipolar disorder. Acta Psychiatr Scand 2012;125:335-41, doi:http://dx.doi.org/10.1111/j.1600-0447.2011.01830.x.

[7] Fond G, Albis M, Jamain S, Tamouza R, Arango C, Fleischhacker WW. The promise of biological markers for treatment response in first-episode psychosis: a systematic review. Schizophr Bull 2015;41:559-73, doi:http://dx. doi.org/10.1093/schbul/sbv002.

[8] Northoff G, Oin P. How can the brain's resting state activity generate hallucinations? A 'resting state hypothesis' of auditory verbal hallucinations. Schizophr Res 2011;127:202-14, doi:http://dx.doi.org/10.1016/J. SCHRES.2010.11.009.

[9] Wright IC, Rabe-Hesketh S, Woodruff PWR, David AS, Murray RM, Bullmore ET Meta-analysis of regional brain volumes in schizophrenia. Am J Psychiatry 2000;157:16-25, doi:http://dx.doi.org/10.1176/ajp.157.1.16.

[10] Shenton ME, Dickey CC, Frumin M, Mccarley RW. A review of MRI findings in schizophrenia. Schizophr Res 2001;49:

[11] Brugger SP, Howes OD. Heterogeneity and homogeneity of regional brain structure in schizophrenia. JAMA Psychiatry 2017;74:1104, doi:http://dx.doi. org/10.1001/jamapsychiatry.2017.2663.

[12] Tarcijonas G, Sarpal DK. Neuroimaging markers of antipsychotic treatment response in schizophrenia: an overview of magnetic resonance imaging studies. Neurobiol Dis 2018, doi:http://dx.doi.org/10.1016/j.nbd.2018.06.021 Jun 25. pii: S0969-9961(18)30200-6. [Epub ahead of print].

[13] Cavelti M, Kircher T, Nagels A, Strik W, Homan P. Is formal thought disorder in schizophrenia related to structural and functional aberrations in the language network? A systematic review of neuroimaging findings. Schizophr Res 2018; 199:2-16, doi:http://dx.doi.org/10.1016/j.schres.2018.02.051.

[14] Kapur S. Psychosis as a state of aberrant salience: a framework linking biology, phenomenology, and pharmacology in schizophrenia. Am J Psychiatry 2003;160:13-23, doi:http://dx.doi.org/10.1176/appi.ajp.160.1.13.

[15] Lee SK, Chun JW, Lee JS, Park HJ, Jung YC, Seok JH, et al. Abnormal neural processing during emotional salience attribution of affective asymmetry in patients with schizophrenia. PLoS One 2014;9:1-8, doi:http://dx.doi.org/ 10.1371/journal.pone.0090792.

[16] Palaniyappan L, Simmonite M, White TP, Liddle EB, Liddle PF. Neural primacy of the salience processing system in schizophrenia. Neuron 2013;79:814-28, doi: http://dx.doi.org/10.1016/j.neuron.2013.06.027.

[17] Pankow A, Katthagen T, Diner S, Deserno L, Boehme R, Kathmann N, et al Aberrant salience is related to dysfunctional self-referential processing in psychosis. Schizophr Bull 2016;42:67-76, doi:http://dx.doi.org/10.1093/ schbul/sbv098.

[18] Roiser JP, Howes OD, Chaddock CA, Joyce EM, McGuire P. Neural and behavioral correlates of aberrant salience in individuals at risk for psychosis. Schizophr Bull 2013;39:1328-36, doi:http://dx.doi.org/10.1093/schbul/sbs147.

[19] Smieskova R, Roiser JP, Chaddock CA, Schmidt A, Harrisberger F, Bendfeldt K, et al. Modulation of motivational salience processing during the early stages of psychosis. Schizophr Res 2014;166:17-23, doi:http://dx.doi.org/10.1016/j. schres.2015.04.036.

[20] Kani AS, Shinn AK, Lewandowski KE, Öngür D. Converging effects of diverse treatment modalities on frontal cortex in schizophrenia: a review of longitudinal functional magnetic resonance imaging studies. J Psychiatr Res 2017;84:256-76, doi:http://dx.doi.org/10.1016/j.jpsychires.2016.10.012.

[21] Gray GE. Concise guide to evidence-based psychiatry. American Psychiatric Pub; 2004.

[22] Moher D, Liberati A, Tetzlaff J, Altman DG, PRISMA Group. Preferred reporting items for systematic reviews and meta-analyses: the PRISMA statement. PLoS Med 2009;6:e1000097, doi:http://dx.doi.org/10.1371/journal.pmed.1000097.

[23] Snitz BE, MacDonald A, Cohen JD, Cho RY, Becker T, Carter CS. Lateral and medial hypofrontality in first-episode schizophrenia: functional activity in a medication-naive state and effects of short-term atypical antipsychotic treatment. Am J Psychiatry 2005;162:2322-9, doi:http://dx.doi.org/10.1176/ appi.ajp.162.12.2322.

[24] Reske M, Kellermann T, Habel U, Jon Shah N, Backes V, von Wilmsdorff M, et al Stability of emotional dysfunctions? A long-term fMRI study in first-episode schizophrenia. J Psychiatr Res 2007;41:918-27, doi:http://dx.doi.org/10.1016/j. jpsychires.2007.02.009.

[25] Ikuta T, Robinson DG, Gallego JA, Peters BD, Gruner P, Kane J, et al. Subcortical modulation of attentional control by second-generation antipsychotics in first-episode psychosis. Psychiatry Res - Neuroimaging 2014;221:127-34, doi: http://dx.doi.org/10.1016/j.pscychresns.2013.09.010.

[26] Wulff S, Nielsen MØ, Svarer C, Rostrup E, Glenthøj BY, Pinborg L, et al. The relation between dopamine D2 receptor blockade and the brain reward system: a longitudinal study of first-episode schizophrenia patients. Psychol Med 2019;1-9, doi:http://dx.doi.org/10.1017/s0033291718004099.

[27] Niendam TA, Ray KL, Iosif A-M, Lesh TA, Ashby SR, Patel PK, et al. Association of age at onset and longitudinal course of prefrontal function in youth with 
schizophrenia. JAMA Psychiatry 2018;75:1252, doi:http://dx.doi.org/10.1001/ jamapsychiatry.2018.2538.

[28] Hu M-L, Zong X-F, Zheng J-J, Pantazatos SP, Miller JM, Li Z-C, et al. Short-term effects of risperidone monotherapy on spontaneous brain activity in firstepisode treatment-naïve schizophrenia patients: a longitudinal fMRI study. Sc Rep 2016;6:34287, doi:http://dx.doi.org/10.1038/srep34287.

[29] Li F, Lui S, Yao L, Hu J, Lv P, Huang X, et al. Longitudinal changes in resting-state cerebral activity in patients with first-episode schizophrenia: a 1-year followup functional MR imaging study. Radiology 2016;279:867-75, doi:http://dx. doi.org/10.1148/radiol.2015151334.

[30] van Veelen NMJ, Vink M, Ramsey NF, van Buuren M, Hoogendam JM, Kahn RS. Prefrontal lobe dysfunction predicts treatment response in medication-naive first-episode schizophrenia. Schizophr Res 2011;129:156-62, doi:http://dx. doi.org/10.1016/j.schres.2011.03.026.

[31] Nielsen MO, Rostrup E, Wulff S, Bak N, Broberg BV, Lublin $\mathrm{H}$, et al. Improvement of brain reward abnormalities by antipsychotic monotherapy in schizophrenia. Arch Gen Psychiatry 2012;69:1195-204, doi:http://dx.doi. org/10.1001/archgenpsychiatry.2012.847.

[32] Bergé D, Carmona S, Salgado P, Rovira M, Bulbena A, Vilarroya O. Limbic activity in antipsychotic naïve first-episode psychotic subjects during facial emotion discrimination. Eur Arch Psychiatry Clin Neurosci 2014;264:271-83, doi:http://dx.doi.org/10.1007/s00406-013-0465-5.

[33] Anticevic A, Hu X, Xiao Y, Hu J, Li F, Bi F, et al. Early-course unmedicated schizophrenia patients exhibit elevated prefrontal connectivity associated with longitudinal change. J Neurosci 2015;35:267-86, doi:http://dx.doi.org/ 10.1523/JNEUROSCI.2310-14.2015.

[34] Keedy SK, Reilly JL, Bishop JR, Weiden PJ, Sweeney JA. Impact of antipsychotic treatment on attention and motor learning systems in first-episode schizophrenia. Schizophr Bull 2015;41:355-65, doi:http://dx.doi.org/10.1093/ schbul/sbu071.

[35] Sarpal DK, Robinson DG, Lencz T, Argyelan M, Ikuta T, Karlsgodt K, et al. Antipsychotic treatment and functional connectivity of the striatum in firstepisode schizophrenia. JAMA Psychiatry 2015;72:5, doi:http://dx.doi.org/ 10.1001/jamapsychiatry.2014.1734.

[36] Ikuta T, Robinson DG, Gallego JA, Peters BD, Gruner P, Kane J, et al. Subcortical modulation of attentional control by second-generation antipsychotics in first-episode psychosis. Psychiatry Res Neuroimaging 2014;221:127-34, doi: http://dx.doi.org/10.1016/j.pscychresns.2013.09.010.

[37] Li F, Lui S, Yao L, Hu J, Lv P, Huang X, et al. Longitudinal changes in resting-state cerebral activity in patients with first-episode schizophrenia: a 1-year followup functional MR imaging study. Radiology 2016;279:867-75, doi:http://dx. doi.org/10.1148/radiol.2015151334.

[39] Hu M-L, Zong X-F, Zheng J-J, Pantazatos SP, Miller JM, Li Z-C, et al. Short-term effects of risperidone monotherapy on spontaneous brain activity in firstepisode treatment-naïve schizophrenia patients: a longitudinal fMRI study. Sci Rep 2016;6:34287, doi:http://dx.doi.org/10.1038/srep34287.

[40] Liemburg EJ, Knegtering H, Klein HC, Kortekaas R, Aleman A. Antipsychotic medication and prefrontal cortex activation: a review of neuroimaging findings. Eur Neuropsychopharmacol 2012;22:387-400, doi:http://dx.doi.org/ 10.1016/j.euroneuro.2011.12.008.
[41] Cadena EJ, White DM, Kraguljac NV, Reid MA, Maximo JO, Nelson EA, et al. A longitudinal multimodal neuroimaging study to examine relationships between resting state glutamate and task related BOLD response in schizophrenia. Front Psychiatry 2018;9:1-11, doi:http://dx.doi.org/10.3389/ fpsyt.2018.00632.

[42] Blasi G, Popolizio T, Taurisano P, Caforio G, Romano R, Di Giorgio A, et al. Changes in prefrontal and amygdala activity during olanzapine treatment in schizophrenia. Psychiatry Res 2009;173:31-8, doi:http://dx.doi.org/10.1016/j. pscychresns.2008.09.001.

[43] Duan H-F, Gan J-L, Yang J-M, Cheng Z-X, Gao C-Y, Shi Z-J, et al. A longitudinal study on intrinsic connectivity of hippocampus associated with positive symptom in first-episode schizophrenia. Behav Brain Res 2015;283: 78-86, doi:http://dx.doi.org/10.1016/j.bbr.2015.01.022.

[44] Dietsche B, Kircher T, Falkenberg I. Structural brain changes in schizophrenia at different stages of the illness: a selective review of longitudinal magnetic resonance imaging studies. Aust N Z J Psychiatry 2017;51:500-8, doi:http://dx. doi.org/10.1177/0004867417699473.

[45] Abbott CC, Jaramillo A, Wilcox CE, Hamilton DA. Antipsychotic drug effects in schizophrenia: a review of longitudinal FMRI investigations and neural interpretations. Curr Med Chem 2013;20:428-37, doi:http://dx.doi.org/ 10.1016/j.biotechadv.2011.08.021.Secreted.

[46] Cao H, Chén OY, Chung Y, Forsyth JK, McEwen SC, Gee DG, et al. Cerebellothalamo-cortical hyperconnectivity as a state-independent functional neural signature for psychosis prediction and characterization. Nat Commun 2018;9:, doi:http://dx.doi.org/10.1038/s41467-018-06350-7.

[47] Zhou Y, Wang Z, Zuo X-N, Zhang H, Wang Y, Jiang T, et al. Hyper-coupling between working memory task-evoked activations and amplitude of spontaneous fluctuations in first-episode schizophrenia. Schizophr Res 2014;159:80-9, doi:http://dx.doi.org/10.1016/J.SCHRES.2014.07.023.

[48] Aguilar EJ, Corripio I, García-Martí G, Grasa E, Martí-Bonmatí L, Gómez-Ansón $\mathrm{B}$, et al. Emotional fMR auditory paradigm demonstrates normalization of limbic hyperactivity after cognitive behavior therapy for auditory hallucinations. Schizophr Res 2017, doi:http://dx.doi.org/10.1016/j. schres.2017.07.024.

[49] Mwansisya TE, Hu A, Li Y, Chen X, Wu G, Huang X, et al. Task and resting-state fMRI studies in first-episode schizophrenia: a systematic review. Schizophr Res 2017;189:9-18, doi:http://dx.doi.org/10.1016/j. schres.2017.02.026.

[50] Smitha KA, Akhil Raja K, Arun KM, Rajesh PG, Thomas B, Kapilamoorthy TR, et al. Resting state fMRI: a review on methods in resting state connectivity analysis and resting state networks. Neuroradiol J 2017;30:305-17, doi:http:// dx.doi.org/10.1177/1971400917697342.

[51] Quattrone D, Di Forti M, Gayer-Anderson C, Ferraro L, Jongsma HE, Tripoli G, et al. Transdiagnostic dimensions of psychopathology at first episode psychosis: findings from the multinational EU-GEI study. Psychol Med 2018;114, doi:http://dx.doi.org/10.1017/S0033291718002131.

[52] Mezquida G, Cabrera B, Bioque M, Amoretti S, Lobo A, González-Pinto A, et al. PEPs group. The course of negative symptoms in first-episode schizophrenia and its predictors: a prospective two-year follow-up study. Schizophr Res 2017;189:84-90, doi:http://dx.doi.org/10.1016/2017.01.047. 